\title{
Modelling and Simulation of the Electric Arc Furnace Processes
}

\author{
Vito Logar \\ Faculty of electrical engineering, University of Ljubljana, Slovenia, vito.logar@fe.uni-lj.si
}

\begin{abstract}
Market demands on steel quality, price and production times dictate an introduction of technological innovations regarding the electric arc furnace (EAF) steelmaking. A developing field with significant potential is related to the advanced software support of the EAF operation, combining monitoring and proper control of the EAF. Such systems include process models, capable of continuous estimation of the unmeasured process values, such as chemical compositions and temperatures of the steel, slag and gas. The paper briefly presents the features of all developed EAF models, which are used together with the measured EAF data to estimate the unmeasured process values. The models are mainly implemented using non-linear, time-variant ordinary differential equations. The parameterization of the models was performed using the available EAF data, such as temperatures, steel and slag compositions, melting programs etc. The validation results that were performed using measured EAF data indicate high levels of estimation accuracy of all crucial steel-recycling values and processes. The accuracy of the presented models is in the range of $+/-15 \mathrm{~K}$ for steel temperature and $+/-10 \%$ for steel composition. Thus, accuracy of the models allows them to be used in broader software environments, such as soft sensors for process monitoring, optimization and operator decision support.
\end{abstract}

Keywords: electric arc furnace, EAF, modelling, simulation, validation

\section{Introduction}

Current market demands on steel quality, price and production times dictate an introduction of several technological innovations regarding the electric arc furnace (EAF) steelmaking. An emerging field with huge potential, but yet rather unexplored, is also advanced software support of the EAF operation. Running in parallel to the EAF process such systems allow online monitoring, fault detection and even model-based control of the process. Using such systems in parallel to the actual EAF process can have several advantages in comparison to the manual EAF operation, arising from the nature of the steel-melting process. As known, several crucial process values are hard to measure continuously, such as temperatures and chemical compositions of the steel, slag and gas etc. Using EAF process models, which integrate all significant EAF phenomena and use available EAF data to calculate the missing process values, results in a system, which is able to estimate the process values with sufficient accuracy. In this manner, better insight to the melting process can be established and consequently a more optimal operation of the EAF can be performed.

The paper presents an overview of the proposed EAF model, including electrical, hydraulic, masstransfer, heat-transfer and chemical submodules in terms of modelling approach, modelling detail and schematic representations of the model structure. Since the mathematical models of the EAF have already been developed, validated and extensively described (Logar et al 2011, 2012) the paper presents only the key characteristics of each separate submodule and its importance for the overall accuracy of the calculations. Furthermore, the paper discusses possible and necessary upgrades of the models to implement them in processoptimization and decision-support frameworks. The aim of those is to present an EAF operation-support tool, which will be running in parallel to the EAF process and will be used for enhancement of the operation, such as: a) EAF operation monitoring based on soft-sensing technology, allowing a better insight to the melting process and consequently more optimal control of the EAF; b) process-optimization based on process models, optimizing the melting programs, according to the current state in the EAF; c) operator decision support, combining the advantages of model-based soft sensors and process optimization in one solution, representing the highest level of EAF software support.

\section{Modelling of the EAF processes in general}

Section The literature review in the field of modelling, optimization and control of the electric arc furnaces shows that many different models and engineering approaches studying the EAF processes have been developed. Most of these are focused on particular processes of the EAF and were developed for the purpose of the field research or simulation of the EAF operation. A few models were designed especially for their implementation into industrial applications as an operator-support tool for monitoring of the recycling process and thus easier decision making and control of 
the processes. First models associated with the EAF processes were introduced back in 1980s and were functionally extremely limited. Modern models have progressed in their complexity, usability and accuracy and are also used in industrial applications for monitoring of the EAF during the steel-melting process. Below, some of the most relevant research and practical applications in the field of modelling, optimization and control of the EAF processes are described.

Woodside (1970) introduces a concept for optimal EAF control, based on Pontryagin approach and uses it for optimization of the energy input during coke injection. The simplified model was introduced in 1970 and was able to estimate bath temperature and carbon concentration. Montanari et al (1994), Tseng et al (1997), Collantes-Bellido and Gomez (1997) introduce mathematical models describing the electrical part of the EAF and the impact of the EAF operation on electrical grids in terms of disturbances (flickers) and their elimination.

In 1999, Bekker et al (1999) develops a mathematical model implementing thermodynamic relations for the purposes of EAF-process simulation. The model is simplified and assumes that all available heat is transferred directly to the steel bath and further from the bath to the solid steel. Although it addresses some important chemical reactions and the released energy, the presented simulation results are not validated and thus applicable only with limitations. Nonetheless, the Bekker model represents one of the first attempts to model all crucial processes of the EAF. Additionally, Bekker et al (2000) introduces a concept of model-predictive EAF control (MPC).

Oosthuizen et al (2001, 2004) designs a mathematical model of the EAF processes derived from the Bekker model. Using a more complex modelling approach, the proposed model gains on estimated offgas temperature accuracy and allows a calculation of the slag foaming. Furthermore, optimal controller is introduced, which should control the furnace in a manner to reduce its operational costs. Similarly to Bekker, a simulation study involving a model-based control (MPC) is performed on the model for the purposes of cost reduction.

One of the most sophisticated EAF models up to 2005 was introduced by MacRosty and Swartz (2005, 2007) and used for optimization of the EAF process. The model considers the complete EAF and includes chemical, mass- and heat-transfer processes. Due to modelling simplifications, the EAF layout is divided into four zones with similar physical characteristics. Chemical reactions in each zone are based on molarmass equilibria, while the overall model is based on energy and mass equilibrium. The model was validated using the measured operational data and can be used to estimate bath temperature, bath composition and slag composition. Further on, the model is implemented in a simulation study to optimize the operational costs of the EAF. The authors report of several issues regarding the optimization procedure and its unreliability.

Logar et al $(2011,2012)$ introduce complex EAF models, including electrical, hydraulic, chemical, heatand mass- transfer processes. The models are based on fundamental physical laws and are validated on measured operational data of the EAF. The results show high levels of similarity between the measured and the simulated data. The combination of all developed models in one functional model represents the most complex approach to EAF modelling found in literature. Many studies have been performed in the field of numerical modelling of the EAF. The field has been established as a new, fast emerging science and engineering discipline that encompasses computational solid mechanics (Fung et al, 2001) and fluid mechanics (Schiestel, 2008), connected with solidification phenomena (Dantzig et al, 2009, Glicksman, 2010), allotropic transformations phenomena (Hazotte, 2003), and put into the context of computational microstructure evolution (Janssens et al, 2007) in processes like casting (Fredriksson and Åkerlind, 2006), heat treatment (Gür and Pan, 2009) etc. The use of numerical modelling proved to be an efficient approach for modelling the relations between bath stirring, fluid flow and electromagnetic (EM) forces. Due to the complex coupling between flow and EM forces, numerical modelling is the most economical way of analyzing, optimizing and developing new applications. Many modern industrial processes, such as electrical arc furnaces, rely on findings of EM, heat-, mass-transfer and metallurgical science. Their interconnections are currently not sufficiently understood and computationally modelled.

Furthermore, modelling approaches to gas-phase phenomena (Meier et al, 2015, Kolagar et al, 2015) and EAF off-gas heat recovery have been proposed (Gandt et al, 2016).

The implementation of the mathematical models in industrial applications can be found at renowned EAF manufacturers and users, such as Tenova, Siemens VAI, SMS Siemag, Centre de Recherche Métallurgiques (CRM), ArcelorMittal and BFI (Clerici et al, 2008, Dorndorf et al, 2007, Khan et al, 2013, Natschläger et al, 2008 and Nyssen et al, 2007). The developed models vary in modelling approach, modelling detail, usability, accuracy and types of input data used for estimating the process values. Reviewing the available literature, most of these models are based on static calculations using statistical or regression methods, i.e. SMS Siemag, BFI and Tenova. The model, based on dynamic modelling approach was introduced by CRM. It relies on fundamental laws of thermodynamics and is used to estimate the end-point bath temperature. It is claimed that the accuracy of the model is $+/-50 \mathrm{~K}$, which 
indicates that further improvements of the model are possible.

The literature review reveals that all models used in industrial applications are designed solely for estimation of the process values, while no support to the operators in the sense of optimal control is given. Thus, the main challenge in EAF operation, i.e. determination of optimal melting programs, times and amounts of charged materials, is therefore still left to the operator and his experience.

Regarding the literature review, a design of the overall EAF process model was initiated, incorporating all crucial EAF processes and focusing on accuracy and usability of the obtained solution for further development and its inclusion to several other software environments.

\section{Modelling approach}

\subsection{General}

The models as presented in this paper have been developed according to the fundamental physical laws by means of non-linear, time-variant, first order differential equations; although, several other approaches could be implemented as well. The selected approach has its advantages and drawbacks when compared to other possibilities; however, the possibility to use the developed models with as many EAF designs as possible was the main aim of the study and for this reason the models are based on fundamental mathematical/physical approaches. The model can be presented schematically as in Fig. 1.

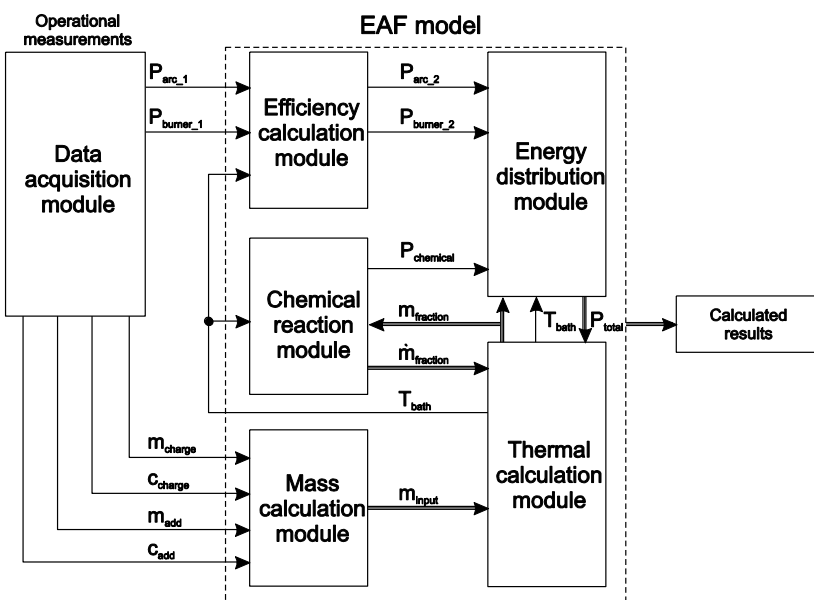

Figure 1: Schematic presentation of the developed EAF models

The presented model as shown in Fig. 1 comprises mathematical descriptions of all main physical processes appearing during the steel-recycling process, i.e. electrical, hydraulic, thermal (including radiation), chemical and mass transfer. As shown in Fig. 1, the model for estimation of the EAF process values is composed of several modules, which contain mathematical relations describing the physical properties of the EAF steel melting process and the corresponding model parameters. The calculations are grouped in submodules in order to simplify the model structure and assure low computational loads.

Due to complexity of the modelled processes and in order to simplify the obtained models, the EAF layout has been divided into several zones, assuming that each zone is homogenous and possesses equal physical characteristics, such as temperatures, densities, heat transfer coefficients etc. The zones used in the model are solid steel, liquid steel, solid slag, liquid slag, gas, roof and walls, as shown in Fig. 2.

According to the above, calculations of a separate submodule are limited only to certain zones, i.e. electrical and hydraulic models appear in no zone directly, heat-transfer model appears in all zones, mass transfer model appears in solid steel, liquid steel, solid slag, liquid slag and gas zones, and the chemical model appears in liquid steel, liquid slag and gas zones.

\subsection{Model characteristics}

Each of the above models utilizes different physical laws and mathematical equations in order to obtain the values needed by other models or as an end result/estimation. The electrical and hydraulic models can be characterized by the following:

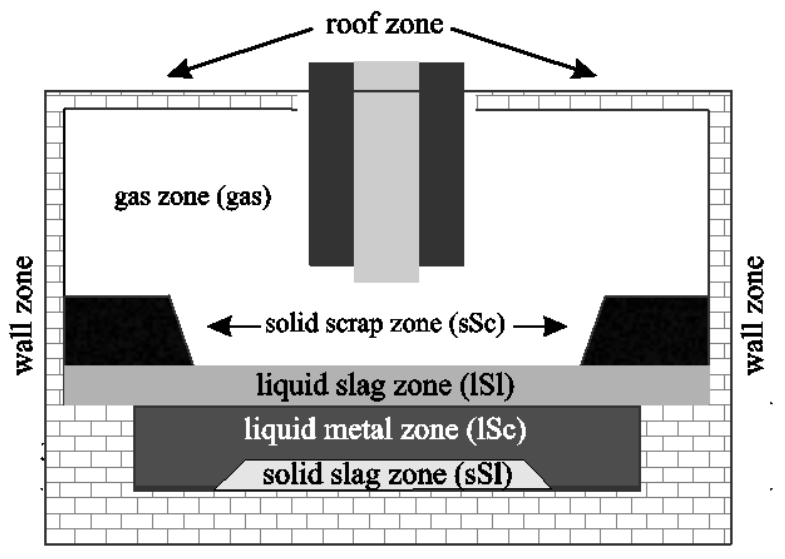

Figure 2: Division of the EAF layout to different zones

- all electrical values are calculated using harmonic analysis, i.e. in complex space,

- Cassie-Mayr arc model (1st order ODEs) is used with additional variable Lorentz noise,

- the models utilize transformer and reactor taps, resistances/reactances of lines, transformer, arcs and steel, all electrical values (voltages, currents, powers, energies, power factors, impedances etc.),

- electrode control is carried out using a hydraulic model and three independent PI controllers,

- the model parameters are variable for different stages of the melting process, i.e. electrode bore-down, melting, flat bath. 
The heat-transfer model can be characterized by the following:

- the melting process is divided to different phases of the melt-down (electrode bore-down, exposing panels, flat bath etc.)

- $1^{\text {st }}$ order ODEs are used to calculate the temperatures based on energy input/output balances

- heat-transfers are utilized to each zone from: arcs, burners, chemical reactions, volatile oxidation, electrode oxidation and other zones,

- heat losses are utilized due to cooling of the furnace, offgas extraction, steel and slag enthalpy,

- implementation of geometry supported (view-factor based) radiative heat exchange,

- taking into the account temperature-dependent burner efficiency and continuous transitions between the zones (geometry supported).

The mass-transfer model can be characterized by the following:

- the melting process is divided to different phases of melt-down (electrode bore-down, exposing panels, flat bath etc.)

- $1^{\text {st }}$ order ODEs are used to calculate mass transfers based on temperature levels (melting) and energy input/output balances,

- elements and compounds which are taken into the account in calculations are:

- steel zone: Fe, C, Si, Cr, Mn, P

- slag zone: $\mathrm{FeO}, \mathrm{SiO}_{2}, \mathrm{MnO}, \mathrm{Cr}_{2} \mathrm{O}_{3}, \mathrm{CaO}, \mathrm{MgO}$, $\mathrm{Al}_{2} \mathrm{O}_{3}, \mathrm{P}_{2} \mathrm{O}_{5}$

- gas zone: $\mathrm{N}_{2}, \mathrm{O}_{2}, \mathrm{CO}, \mathrm{CO}_{2}, \mathrm{CH}_{4}$ (gas burners),

- implementation of reversible dynamics (cooling and solidification of the steel),

-calculation of mass transfers due to: melting, charging and slag addition, oxygen-fuel burners, oxygen lancing, carbon injection and chemical reactions.

The chemical model can be characterized by the following:

- implementation of all main chemical reactions appearing in the steel-melting process (oxidation/reduction of $\mathrm{Fe}, \mathrm{FeO}, \mathrm{Si}, \mathrm{SiO}_{2}, \mathrm{C}, \mathrm{CO}, \mathrm{Mn}$, $\mathrm{MnO}, \mathrm{Cr}, \mathrm{Cr}_{2} \mathrm{O}_{3}, \mathrm{P}$ and $\mathrm{P}_{2} \mathrm{O}_{5}$ ),

- $1^{\text {st }}$ order ODEs are used to calculate rates of change of elements/compounds based on molar equilibria with reaction equilibria constants dependent on molar composition of the zone,

- utilization of chemical energy exchange due to exothermic and endothermic reactions,

- calculation of foaming slag height based on slag density/viscosity/surface tension and superficial gas velocity $(\mathrm{CO})$ including slag decay,
- calculation of online and endpoint steel/slag/gas compositions and relative pressure.

The parameters of the model (approximately 100) were obtained using known data or conclusions of different studies (transformer taps, resistances/reactances, furnace dimensions, heat capacity coefficients, densities, emissivities, enthalpies of formation, reaction rates, molar masses etc.) or were determined experimentally using the available initial, online or endpoint operational EAF measurements (cathode voltage drops, arc temperatures, arc conductances, arc cooling constants, slag-reactance coefficients, heat-transfer coefficients, specific area coefficients, arc-energy distributions etc.). The validation of the models was carried out using operational EAF measurements, which were obtained during different melting scenarios. In this manner, an accurate model of the actual EAF recycling process was obtained.

\section{Results}

The displayed results show the most important estimations of the process values while operating the EAF, i.e. bath temperatures, steel compositions and slag compositions. Fig. 3 shows the comparison between measured and model simulated values for initial steel mass, endpoint steel mass, power on time and bath temperatures. The results were obtained from several heats and are represented in a form of a mean value with standard deviation.
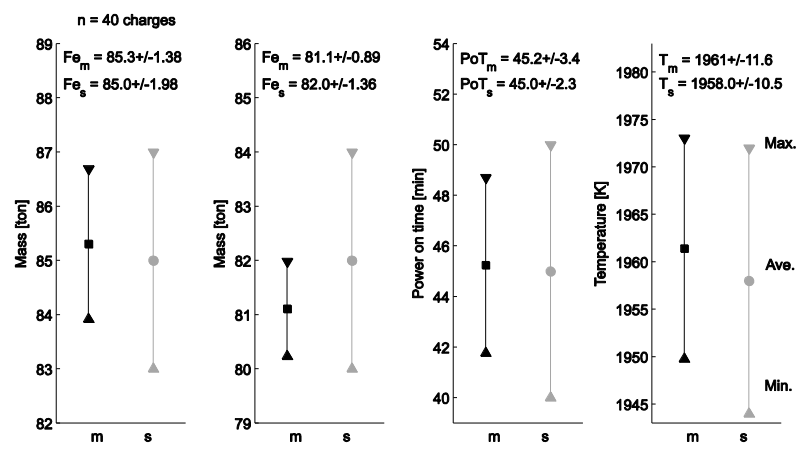

Figure 3: comparison between measured and simulated values for initial (1st) and enpoint (2nd) steel mass, power on time (3rd) and bath temperatures (4th). Black squares and grey circles represent measured and simulated mean values, while black and grey triangles represent measured and simulated standard deviations, respectively.

As can be seen in Fig. 3, all measured and simulated values are similar, both in mean values and in standard deviations. The most important validation values from Fig. 3 are steel yield (difference between the initial and endpoint steel masses) and steel bath temperature. Bath temperature is usually measured one to three times before tapping, while steel yield is determined at 
tapping. Neither of these values is measured continuously during the EAF operation.

Fig. 4 shows the comparison between measured and model simulated endpoint steel composition in a form of a mean value with standard deviation.

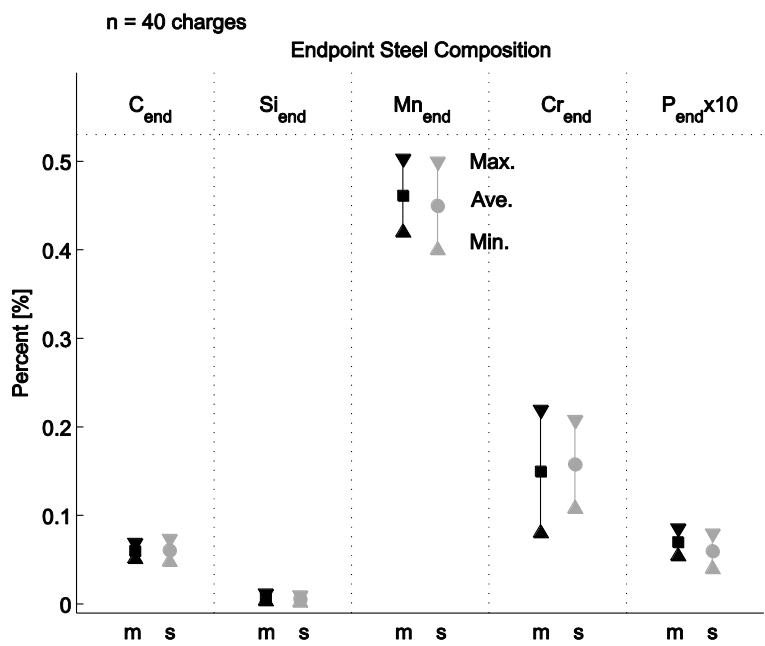

Figure 4: comparison between measured and simulated endpoint chemical compositions of the steel

As can be seen in Fig. 4, all measured and simulated values are similar, both in mean values and in standard deviations. The most important validation value from Fig. 4 is the carbon content in the steel, since carbon percentage is (among others) directly linked to different steel grades produced and has to be determined and contained in proper amount. Complete steel composition is determined at tapping and is otherwise not measured continuously.

Fig. 5 shows the comparison between measured and model simulated endpoint slag composition in a form of a mean value with standard deviation.

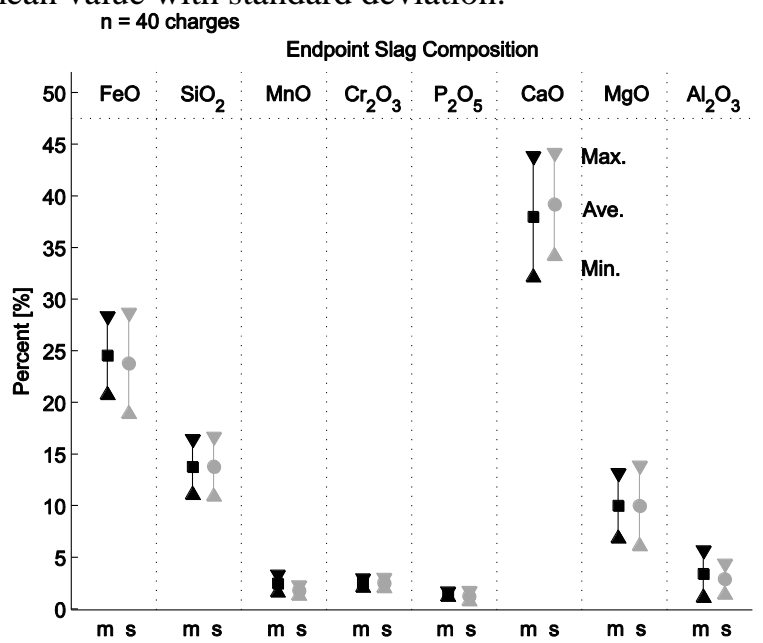

Figure 5: comparison between measured and simulated endpoint chemical compositions of the slag

As can be seen in Fig. 5, all measured and simulated values are similar, both in mean values and in standard deviations. The most important validation value from Fig. 5 are $\mathrm{FeO}, \mathrm{SiO} 2, \mathrm{MnO}, \mathrm{CaO}$ and $\mathrm{MgO}$ contents in the slag, since these compounds define the properties of the slag, which are linked to its foaminess and protective characteristics.

Fig. 6 shows the energy balance as calculated by the proposed model.

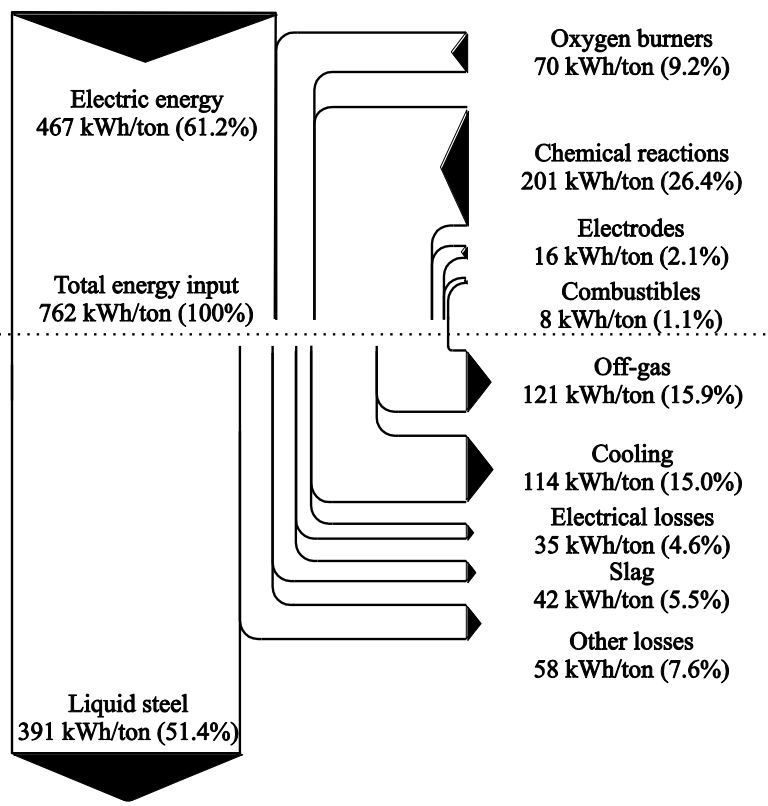

Figure 6: energy balance of the EAF as obtained by the proposed model

As can be seen in Fig. 6, total energy input required to produce 1 ton of steel is approximately $760 \mathrm{kWh}$. More than a half of this energy is represented by electrical energy, while other important sources of energy are oxygen burners and chemical reactions. Regarding the losses of energy, approximately $390 \mathrm{kWh}$ of energy is held by steel enthalpy due to its high temperature. This energy is later lost to the environment as the steel cools down. Furthermore, off-gas extraction and cooling of the furnace vessel also represent an important sinks of energy.

\section{Practical applications of the model}

Due to the nature of the EAF steel-recycling process (high temperatures and electric currents), performance of the crucial process measurements is difficult. Consequently, monitoring and control of the melting process is performed using the operator's experience and is based on indirect measurements (e.g. power-on time, consumed energy, arc stability etc.) and not on the actual conditions in the EAF (e.g. stage of melting, bath composition, bath temperature), which leads to suboptimal operation, i.e. lower energy and raw material efficiency, increased off gas and $\mathrm{CO} 2$ emissions, decreased quality of the steel; and consequently higher operational costs.

Furthermore, operational efficiency is influenced also by variable composition of the input materials (steel scrap, non-metallic additives). The fluctuations in EAF operation can be resolved using a combination of EAF 
process models, optimization techniques and decision support methods. The combination of these methods together with available process measurements forms a supporting system for operation of the EAF. Such a system uses process measurements as inputs, in order to provide a better insight into the current EAF conditions and to suggest the most appropriate action, leading to more efficient operation of the EAF. Using mathematical models, which are designed in compliance with the physical laws and using available measurements as inputs, crucial process values, which are not measured, can be estimated in parallel to the EAF process with high accuracy.

In this manner, an optimal operation of the EAF can be established, leading to higher steel yield, lower energy, raw material and additive consumption, shorter production times, higher steel quality etc. The introduction of such operation indirectly leads to improved economic, ecological and technological aspects of the mills, with such system installed.

\section{Conclusions}

In this paper a brief explanation of the modelling approach to crucial EAF processes as well as its potential use in higher-level applications is presented. Furthermore, some key comparisons between the measured and the simulated values are presented, showing the overall accuracy of the calculations.

The objective of developing a complete EAF model is to use it in application frameworks for different purposes, such as online monitoring, process optimization or operator decision support. Since the description and modelling details are far too great and extend the frame of this paper, all interested readers can refer to the reference list (Logar et al.) for further information.

\section{References}

J. G. Bekker, I. K. Craig, P. C. Pistorius. Modeling and simulation of an electric arc furnace process, ISIJ International, 39(1): 23 - 32, 1999.

J. G. Bekker, I. K. Craig, P. C. Pistorius. Model Predictive Control of an Electric Arc Furnace Off-Gas Process, Control Engineering Practice, 8(4): 445 - 455, 2000.

P. Clerici, F. Dell'Acqua, J. Maiolo, V. Scipolo. Dynamic EAF control using highest performing technology, MPT International - Metallurgical Plant and Technology, 31: 40 - 42, 2008

R. Collantes-Bellido, T. Gómez. Identification and modelling of a three phase arc furnace for voltage disturbance simulation. IEEE Transactions on Power Delivery, 12(4): 1812 - 1817, 1997.

J. Dantzig, M. Rappaz. Solidification, CRC Press, Boca Raton, 2009.

M. Dorndorf, W. Wichert, M. Schubert, J. Kempken, K. Krüger. Ganzheitliche Erfassung und Regelung des
Schmelzprozesses eines Elektrolichtbogenofens, Stahl und Eisen, 127: 63 - 71, 2007.

H. Fredriksson, U. Åkerlind. Materials Processing During Casting, John Wiley, Hoboken, 2006.

Y.C. Fung, P. Tong. Classical and Computational Solid Mechanics, World Scientific, Singapore, 2001.

K. Gandt, T. Meier, T. Echterhof, H. Pfeifer. Heat recovery from EAF off-gas for steam generation: analytical exergy study of a sample EAF batch, Ironmaking \& Steelmaking: Processes, Products and Applications, 43(8): 581 - 587, 2016.

M. E. Glicksman. Principles of Solidification, Springer Verlag, Berlin, 2010.

C. H. Gür, J. Pan (eds.). Thermal Process Modelling of Steel, CRC Press, Boca Raton, 2009

A. Hazotte (ed.). Solid State Transformation and Heat Treatment, Wiley-VCH, Weinheim, 2003.

K. G. F. Janssens, D. Raabe, E. Kozeschnik, M. A. Miodownik, B. Nestler. Computational Materials Engineering - An Introduction to Microstructure Evolution, Elsevier, Amsterdam, 2007.

M. Khan, S. Mistry, V. Scipolo, S. Sun, S. Waterfall. Nextgeneration EAF optimization at ArcelorMittal Dofasco Inc, In AISTech, Iron and Steel Technology Conference and Exhibition, pages 697 - 706, Pittsburgh, USA, 2013, AISTech.

A. H. Kolagar, T. Meier, T. Echterhof, H. Pfeifer. Application of genetic algorithm to improve an electric arc furnace freeboard model based on practical data, International Journal of Engineering Systems Modelling and Simulation, 7(4): $244-255,2015$.

V. Logar, D. Dovzan and I. Škrjanc. Mathematical modeling and experimental validation of an electric arc furnace, ISIJ International, 51(3): 382 - 391, 2011.

V. Logar, D. Dovzan and I. Škrjanc. Modeling and validation of an electric arc furnace: Part 1, heat and mass transfer, ISIJ International, 52(3): 402 - 413, 2012.

V. Logar, D. Dovzan and I. Škrjanc. Modeling and validation of an electric arc furnace: Part 2, thermochemistry, ISIJ International, 52(3): 414 - 424, 2012.

V. Logar and I. Škrjanc. Modeling and validation of the radiative heat transfer in an electric arc furnace, ISIJ International, 52(7): 1225 - 1232, 2012.

R. D. M. MacRosty, C. L. E. Swartz. Dynamic modeling of an industrial electric arc furnace, Industrial \& engineering chemical research, 44(21): 8067 - 8083, 2005.

R. D. M. MacRosty, C. L. E. Swartz. Dynamic optimization of electric arc furnace operation, AIChE Journal, 53(3): 640 $-653,2007$.

T. Meier, A. H. Kolagar, T. Echterhof, H. Pfeifer. Gas phase modeling and simulation in an electric arc furnace process model for detailed off-gas calculations in the dedusting system, In Steelsim - International Conference Simulation and Modelling of Metallurgical Processes in Steelmaking 2015, Bardolino, Italy, 2015, AIM.

G. C. Montanari, M. Loggini, A. Cavallini, L. Pitti, D. Zaninelli. Arc-furnace model for the study of flicker compensation in electrical networks, IEEE Transactions on Power Delivery, 9(4): 2026 - 2036, 1994. 
S. Natschläger, S. Dimitrov, K. Stohl. EAF process optimization: theory and real results, Archives of Metallurgy and Materials, 53(2): 373 - 378, 2008.

P. Nyssen, G. Monfort, J. L. Junque, M. Brimmeyer, P. Hubsch, J. C. Baumert. Use of a dynamic metallurgical model for the on-line control and optimization of the electric arc furnace, In Steelsim - International Conference Simulation and Modelling of Metallurgical Processes in Steelmaking 2011, Graz, Austria, 33-38, 2011, AIM.

D. J. Oosthuizen, J. H. Viljoen, I. K. Craig, P. C. Pistorius. Modeling of the off-gas exit temperature and slag foam depth of an electric arc furnace, ISIJ International, 41(4): 399 - 401, 2001.

D. J. Oosthuizen, I. K. Craig, P. C. Pistorius. Economic evaluation and design of an electric arc furnace controller based on economic objectives, Control engineering practice, 12(3): 253 - 265, 2004.

R. Schiestel. Modeling and Simulation of Turbulent Flows, Willey, Hoboken, 2008.

K. J. Tseng, Y. Wang, D. M. Vilathgamuwa. An experimentally verified hybrid Cassie-Mayr electric arc model for power electronics simulations. IEEE Transactions on Power Electronics, 12(3): 429 - 436, 1997.

C. M. Woodside. Singular arcs occurring in optimal electric steel refining, IEEE transactions on automatic control, 15(5): 549 - 556, 1970. 